\title{
A Density Functional Theory Study of Oxygen Adsorption at Silver Surfaces: Implications for Nanotoxicity
}

\author{
Brahim Akdim, Saber Hussain, and Ruth Pachter \\ Air Force Research Laboratory, Wright-Patterson Air Force Base, \\ Ohio 45433, USA \\ Brahim.Akdim@wpafb.af.mil, Saber.Hussain@wpafb.af.mil, \\ Ruth.Pachter@wpafb.af.mil
}

\begin{abstract}
The formation of superoxide at $\operatorname{Ag}(100)$ and $\operatorname{Ag}(111)$ surfaces for cluster and periodic slab models is studied by applying first-principles density functional theory calculations, including ab-initio molecular dynamics. Adsorption energies and structural parameters are discussed in detail. Charge transfer analyses indicate that O2- preferentially forms on clusters, particularly at an $\operatorname{Ag}(100)$ surface.
\end{abstract}

Keywords: Density Functional Theory, Ag Nanoparticles, Oxygen Adsorption.

\section{Introduction}

The potential for toxicity in nanomaterials has been recently summarized by Nel et al., [1], particularly regarding reactive oxygen species (ROS) generation, pointing out that under conditions of excess ROS production, natural antioxidant defenses may be overwhelmed, which can impair or destroy cell proteins, lipids and DNA, thus leading to deterioration of cell function, or toxicity [2]. The effects of oxidative stress on cell behavior in vivo and in cell culture, where glutathione (GSH) is depleted, were recently described [3]. Indeed, concerns regarding health safety of nanoparticles have been consistently growing in the last few years $[4.5,6,7,8]$. However, the mechanisms by which nanoparticles generate ROS are still unclear. For example, it was proposed that the early phase of ROS production is due to redox cycling chemistry, while mitochondria are responsible for the late and progressive increase in $\mathrm{O}_{2}{ }^{-}$radicals [9]. Possible mechanisms range from $\mathrm{H}_{2} \mathrm{O}_{2}$ production, generation of superoxide anion by redox cycling reactions, electron-acceptor active groups for superoxide anion generation, catalyzing electron transport to oxygen, presence of metal nanoparticles that may induce Fenton-like chemistry to generate hydroxyl radicals from $\mathrm{H}_{2} \mathrm{O}_{2}$, or light activation, e.g. of $\mathrm{TiO}_{2}$ or $\mathrm{C}_{60}$ for the formation of superoxides [9].

At the same time, the antibacterial effect of silver nanoparticles resulted in their extensive application in health and home products, therefore making an evaluation of their toxicity an important undertaking, motivating animal experimental studies, and also the development of means for distribution of specific concentrations of silver nanoparticles [10]. Toxicity of Ag nanoparticles (15-50 nm in diameter) was recently 
demonstrated in vitro [11], where an investigation of the role of oxidative stress has shown increased ROS generation, noting differences due to the Ag nanoparticle size.

Of course, the interaction of oxygen with silver has been studied for a long time, particularly as Ag is one of the best partial oxidation catalysts for industrial reactions, including the oxidative coupling of methane, partial dehydrogenation of methanol to formaldehyde, and epoxidation of ethylene, for example, as investigated by Avdeev and co-workers [12, and references therein], in order to explain the enhanced reactivity, also by understanding the role of subsurface oxygen upon dissociation, for example, theoretically $[13,14,15$, and references therein]. It has also been shown that an electron is transferred to $\mathrm{O}_{2}$, where the reduction of the dioxygen results in a superoxide anion metastable species, as a precursor for its dissociation $[16,17,18]$, also depending on the silver facet. It was noted that the $\mathrm{O}-\mathrm{O}$ bond at a silver cluster is weaker than at a bulk surface [19], possibly supporting the supposition that superoxide anions at the surface may result in toxicity for small Ag nanoparticles. Note however that the particles that compose the Ag catalyst, for example, are affected by many surface defects and their chemistry could be different from that of perfect low-Miller-index surfaces, as has been suggested, and studied [20].

In this work, as the first step towards gaining an understanding of the charge transfer characteristics and adsorption of oxygen, applying first principles density functional theory (DFT), we investigated the effects of $\mathrm{O}_{2}$ adsorption at facets of a truncated octahedron (TO) cluster, as observed experimentally [21], and for comparison, also at a $\operatorname{Ag}(100)$ slab, as test problems, which may possibly preliminarily explain, in part, changes in toxicity of Ag nanoparticles of different size. Note, however, that comprehensive simulations to model the system in room temperature will be carried out in the future to further understand this system.

\section{Computational Details}

Calculations were performed with all-electron linear combination of atomic orbitals DFT method as implemented in Dmol3 [22]. The Perdew-Burke-Ernzerhof (PBE) exchange-correlation functional [23] and a double numerical basis set with dfunctions (DND) were applied. For validation, $\mathrm{O}_{2}$ molecular calculations were carried out using unrestricted spin calculations, resulting in an $\mathrm{O}-\mathrm{O}$ distance $\left(r_{\mathrm{O}-\mathrm{O}}\right)$ of $1.22 \AA$ and a dissociation energy of $5.3 \mathrm{eV}$ in the gas phase, in good agreement with experimental results $(1.21 \AA$ and $5.2 \mathrm{eV})$ [24] and a previous theoretical study $(1.24 \AA$ and $5.3 \mathrm{eV})$ [25].

\section{Results and Discussion}

\subsection{Structural Parameters}

Fig. 1 summarizes the optimized structures for $\operatorname{Ag}(100)$ and $\operatorname{Ag}(111)$ surface cluster models, upon oxygen adsorption, as well as for the corresponding slab structures. Structural parameters are listed in Table 1. 
a)

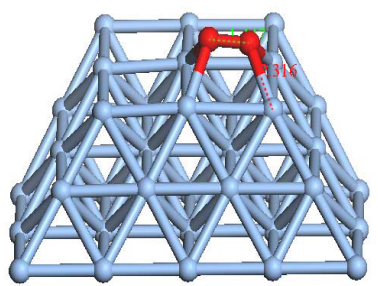

$\mathrm{C}(100)_{1}$

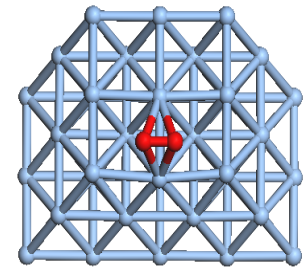

$\mathrm{C}(100)_{2}$

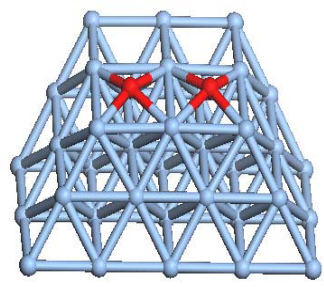

$\mathrm{C}(100)_{3}$

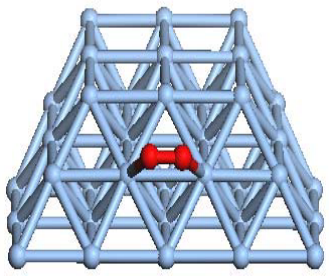

C(111)

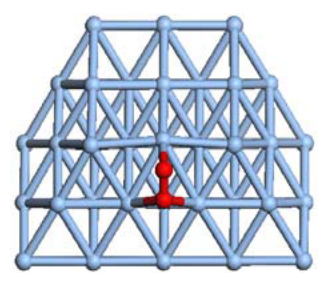

$\mathrm{C}(111)_{2}$

b)

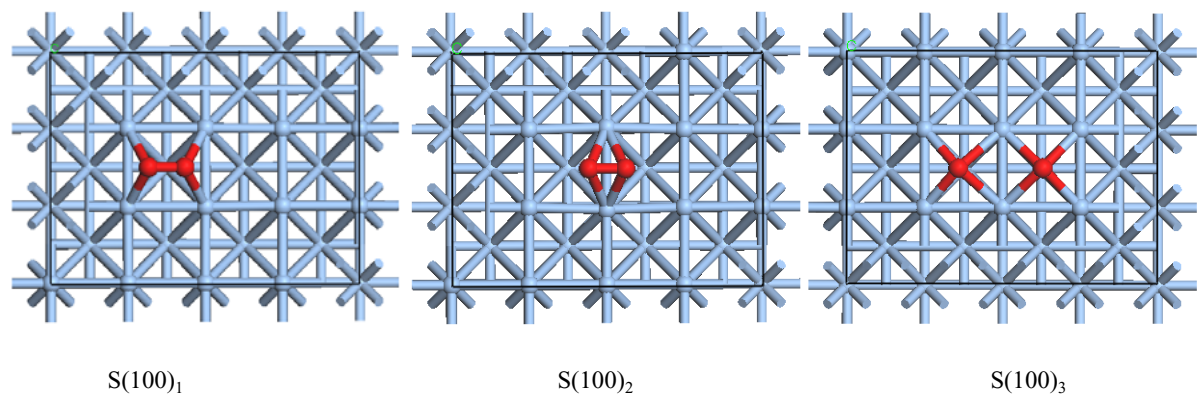

Fig. 1. $\mathrm{O}_{2}$ adsorption on Ag surfaces: (a) TO cluster; (b) $3 \times 4 \mathrm{Ag}$ (100) slab

As shown in Fig. 1, the adsorption sites that were considered for $\mathrm{Ag}(100)$ consisted of $\mathrm{O}_{2}$ chemisorption at the four-fold site $\left(\mathrm{C}(100)_{1}\right)$, a crossed configuration $\left(\mathrm{C}(100)_{2}\right)$, and dissociated $\mathrm{O}_{2}$, where each oxygen occupies a four-fold site $\left(\mathrm{C}(100)_{3}\right)$. In the $\mathrm{Ag}$ (111) plane, we considered a bridged configuration $\left(\mathrm{C}(111)_{1}\right)$ and three-fold adsorption $\left(\mathrm{C}(111)_{2}\right)$. For the TO cluster, a preference in the adsorption of $\mathrm{O}_{2}$ at an $\operatorname{Ag}(100)$ surface was calculated, specifically for configuration $\mathrm{C}(100)_{1}$.

The results show that for model $\mathrm{C}(100)_{1}, r_{O-O}$ distances are consistent with previous work on discerning $\mathrm{O}-\mathrm{O}$ distances upon superoxide formation when adsorbed at $\operatorname{Ag}[16,17,18,26]$, while a shorter distance is noted for the an $\operatorname{Ag}(111)$ surface. Although the $\mathrm{O}-\mathrm{O}$ bond is weakened, charge transfer is less pronounced in 
Table 1. Adsorption energies, Mulliken population analyses, and structural parameters for the TO cluster and slab models

\begin{tabular}{c|cccccc}
\hline & Adsorption & $\mathrm{r}_{\mathrm{O}-\mathrm{O}}(\AA)$ & $\mathrm{r}_{\mathrm{Ag}-\mathrm{O}}(\AA)$ & $\mathrm{r}_{\mathrm{Ag}-\mathrm{Ag}}(\AA)$ & $\begin{array}{c}\text { Mulliken } \\
\text { partial atomic } \\
\text { charges }(\mathrm{e})\end{array}$ & $\begin{array}{c}\text { Adsorption } \\
\text { Energy } \\
\mathrm{kcal} / \mathrm{mol})\end{array}$ \\
\hline$(100)$ & $\mathbf{C}_{\mathbf{1}}$ & 1.45 & 2.33 & 3.11 & $-0.74 / \mathrm{O}_{2}$ & -21.5 \\
& $\mathbf{S}_{\mathbf{1}}$ & 1.42 & 2.32 & 3.08 & $-0.64 / \mathrm{O}_{2}$ & -17.1 \\
& $\mathbf{C}_{\mathbf{2}}$ & 1.41 & 2.45 & 3.14 & $-0.64 / \mathrm{O}_{2}$ & -12.0 \\
& $\mathbf{S}_{\mathbf{2}}$ & 1.42 & 2.38 & 3.19 & $-0.62 / \mathrm{O}_{2}$ & -4.9 \\
& & & & & & -45.0 \\
& $\mathbf{C}_{\mathbf{3}}$ & 3.47 & 2.30 & 3.17 & $-0.77 / \mathrm{O}$ & -40.9 \\
\hline$(111)$ & $\mathbf{S}_{\mathbf{3}}$ & 3.26 & 2.35 & 3.07 & $-0.72 / \mathrm{O}$ & -0.5 \\
& $\mathbf{C}_{\mathbf{1}}$ & 1.34 & 2.32 & 3.16 & $-0.46 / \mathrm{O}_{2}$ & -8.8 \\
& $\mathbf{S}_{\mathbf{2}}$ & 1.37 & $\mathrm{O} 1: 2.25$ & 3.04 & $-0.56 / \mathrm{O}_{2}$ & \\
\hline
\end{tabular}

this case, not yet in the distance range of a superoxide formation. Interestingly, results for a cluster and a slab, carried out for comparison, show somewhat larger $r_{O-O}$ for the cluster, consistent with the previous suggestion that the O-O bond may be weaker at a cluster than on a bulk surface [19]. Ag- $\mathrm{O}$ distances are in relatively good agreement with previously reported results [27,28] for a periodic system, however applying a plane wave basis set. The lengthened $\mathrm{Ag}-\mathrm{Ag}$ distances calculated in the four-fold hollow site for the cluster $(3.17 \AA)$, as compared to the extended system $(3.07 \AA)$, may explain the slight increase of $r_{O-O}$ in $\mathrm{C}(100)_{3}$.

\subsection{Adsorption Energies}

Charged molecular species binding to the silver metal have been proposed as intermediates, namely, the superoxide and peroxide species, suggesting the possibility of long-lived trapped states due to deep potential wells [18]. Indeed, in carrying out ab initio MD simulations (Fig. 2), with runs of about $1 \mathrm{ps,} \mathrm{in} \mathrm{order} \mathrm{to}$ assess preferred configurations, with $\mathrm{C}(111)_{2}$ as the starting configuration, $\mathrm{C}(111)_{1}$ was found to be the stable structure at about $400^{\circ} \mathrm{K}$, with an oxygen atom moving toward the center of the fourfold site, possibly denoting a trapped metastable state and no dissociation.

The characteristics of dissociative oxygen adsorption on silver surfaces has drawn significant interest, because it is an important step in the catalytic oxidation reaction [17,29]. Although a dissociated molecule at temperatures lower than $110^{\circ} \mathrm{K}$ on clusters was shown [19], where dissociation occurs from molecular chemisorbed $\mathrm{O}_{2}{ }^{-}$, the experiments were carried out for very small clusters, up to $25 \mathrm{Ag}$ atoms, noting that a larger energy barrier would be exhibited for a bulk surface. An investigation [30] of the interaction of molecular oxygen with bulk $\mathrm{Ag}(100)$ has shown that although some oxygen molecules adsorb dissociatively at low temperatures, a higher 


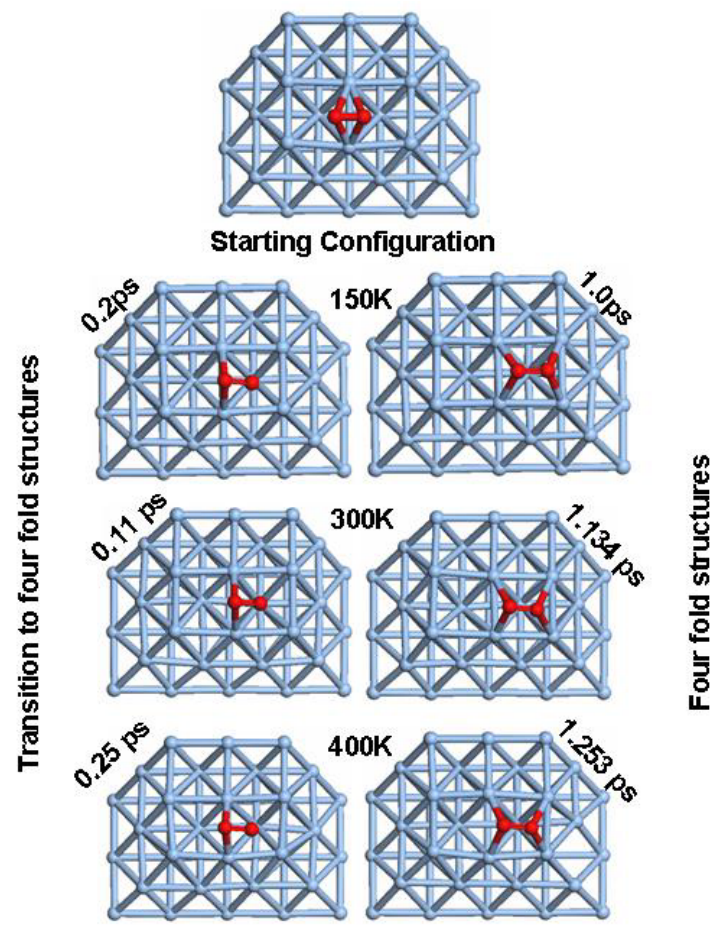

Fig. 2. ab-inito $\mathrm{MD}$ simulations of $\mathrm{O} 2$ adsorption on an $\mathrm{Ag}(100) \mathrm{TO}$ cluster (configuration C(100)2)

pressure and temperature of about $470^{\circ} \mathrm{K}$ are required to achieve larger surfaces with oxygen atom adsorption. Overall, our preliminary results suggest that superoxide species are more likely to form on $\mathrm{Ag}$ clusters, specifically at the $\mathrm{Ag}(100)$ facet. However, conclusive results have yet to be obtained, particularly regarding calculations of barrier heights, and consideration of realistic samples.

\subsection{Charge Transfer}

As expected, our calculations showed charge transfer from Ag surfaces to the adsorbed $\mathrm{O}_{2}$ molecule, where for configuration $\mathrm{C}(100)_{1}$ a larger partial atomic charge $\left(-0.74 / \mathrm{O}_{2}\right)$ than for $\mathrm{C}(100)_{2}\left(-0.64 / \mathrm{O}_{2}\right)$ was calculated (Table 1). A larger charge transfer is consistent with the increase in the $r_{O-O}$ distance, more pronounced for the cluster than for the slab model. A smaller charge transfer for $\mathrm{Ag}(111)$ adsorption, as compared to the $\operatorname{Ag}(100)$ surface, was calculated.

\section{Summary}

In this communication, we presented a DFT first principles study, including MD simulations, to investigate the possibility of superoxide formation on $\operatorname{Ag}(100)$ and 
$\mathrm{Ag}(111)$ surfaces. We found the four-fold adsorption site to be more favorable in $\operatorname{Ag}(100)$ as compared to $\mathrm{C}(100)_{2}$, and also to adsorption at $\operatorname{Ag}(111)$. Because of the lack of comprehensive experimental data on silver nanoparticles, oxygen dissociation mechanisms are yet to be definitively elucidated in comparison with the bulk. The charge transfer results indicate a higher preference for superoxide formation on an $\mathrm{Ag}(100)$ cluster surface, providing the first stage towards attempting to understand ROS formation in silver nanoparticles.

\section{References}

1. Nel, A., Xia, T., Madler, L., Li, N.: Science 311, 622 (2006)

2. Stone, V., Donaldson, K.: Nat. Nanotechnol. 1, 23 (2006)

3. Halliwell, B.: Biochem. Soc. Trans. 35, 1147 (2007)

4. Maynard, A.D., Aitken, R.J., Butz, T., Colvin, V., Donaldson, K., Oberdoerster, G., Philbert, M.: Nature 444, 267 (2006)

5. Oberdester, G., Oberdester, E., Oberdester, J.: Environ. Health Perspect. 113, 823 (2005)

6. Kreyling, W.G., Semmler-Behnke, M., Moller, W.J.: Nanopart. Res. 8, 543 (2006)

7. Tsuji, J.S., Maynard, A.D., Howard, P.C., James, J.T., Lam, C.-W., Warheit, D.B., Santamaria, A.B.: Toxicol. Sci. 89, 42 (2006)

8. Borm, P.J.A., Robbins, D., Haubold, S., Kuhlbusch, T., Fissan, H., Donaldson, K., Schins, R., Stone, V., Kreyling, W., Lademann, J., Krutmann, J., Warheit, D., Oberdorster, E.: Part. Fibre Toxicol. 3 (2006)

9. Xia, T., Kovochich, M., Brant, J., Hotze, M., Sempf, J., Oberley, T., Sioutas, C., Yeh, J.I., Wiesner, M.R., Nel, A.E.: Nano Lett. 6, 1794 (2006)

10. Ji, J.H., Jung, J.H., Kim, S.S., Yoon, J.-U., Park, J.D., Choi, B.S., Chung, Y.H., Kwon, I.H., Jeong, J., Han, B.S., Shin, J.H., Sung, J.H., Song, K.S., Yu, I.J.: Inhalation Toxicol. 19,857 (2007)

11. Hussain, S.M., Hess, K.L., Gearhart, J.M., Geiss, K.T., Schlager, J.J.: Toxicol. in vitro 19, 975 (2005)

12. Avdeev, V.I., Boronin, K.S.V., Zhidomirov, G.M.: J. Mol. Catal. 154, 257 (2000)

13. Xu, Y., Mavrikakis, M.: J. Am. Chem. Soc. 127, 12823 (2005)

14. Li, W.-X., Stamfl, C., Scheffler, M.: Phys. Rev. B 68, 165412 (2003)

15. Michaelides, A., Reuter, K., Scheffler, J.: Vac. Sci. Technol. A 23, 1487 (2005)

16. Campbell, C.T.: Surf. Sci. 157, 43 (1985)

17. Citri, O., Baer, R., Kosloff, R.: Surf. Sci. 351, 24 (1996)

18. Katz, G., Zeiri, Y., Kosloff, R.: Surf. Sci. 425, 1 (1999)

19. Schmidt, M., Masson, A., Brechignac, C.: Phys. Rev. Lett. 91, 243401 (2003)

20. Bonini, N., Kokalj, A., Dal Corsoe, A., de Gironcoli, S., Baroni, S.: Phys. Rev. B 69, 195401 (2004)

21. Harfenist, S.A., Wang, Z.L., Alvarez, M.M., Vezmar, I., Whetten, R.L.: J. Phys. Chem. 100, 13904 (1996)

22. Delley, B.J.: Chem. Phys. 113, 7756 (2000); implemented in Accelyrs Inc.

23. Perdew, J.P., Burke, K., Ernzerhof, M.: Phys. Rev. Lett. 77, 3865 (2006)

24. Weast, R.: CRC Handbook of Chemistry and Physics. CRC Press, Boca Raton (1985)

25. Honkala, K., Laasonen, K.: Phys. Rev. Lett. 84, 705 (2000) 
26. Nakatsuji, H., Nakai, H.: J. C. Phys. 98, 2423 (1993)

27. Wang, Y., Jia., L., Wang, W., Fan, K.: J. Phys. Chem. B, 106, 3662 (2002)

28. Wang, Y., Jia., L., Wang, W., Fan, K.: J. Chem. Phys. 119, 11210 (2003)

29. German, E.D., Shientuch, M.: J. Phys. Chem. A 1097957 (2005)

30. Costine, I., Schmid, M., Schiechl, H., Gajdos, M., Stierle, A., Kumaragurubaran, S., Hafner, J., Dosch, H., Varga, P.: Surf. Sci. 617 (2006) 